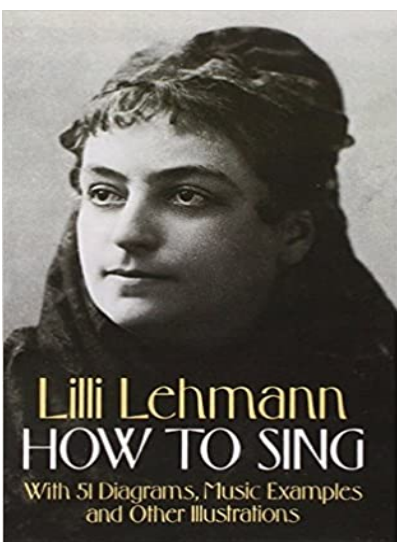

\title{
How to Sing
}

Lilli LEHMANN Dover Publications, New York, 1993,

İngilizce, s. 149

ISBN: 0-486-27501-9

Lilli Lehmann (1848-1929) olağanüstü vokal tekniği ve çok yönlülüğü ile tanınmış Alman operatik soprano olarak döneme damgasını vurmuş, önemli bir şan öğretmenidir. How to Sing isimli bu kitap, 1902 yılında orijinal ismi olan Almanca Meine Gesangskunt olarak yazılmış, daha sonra Richard Aldrich tarafından İngilizceye çevrilerek How to Sing adıyla Mcmillian Company yayınları tarafından yayınlanmıştır. 1993 yılında Dover Publications tarafından revize edilerek tekrar yayınlanmıştır. Kitapta ses eğitimi için bilimsel yöntemlere dayandırılarak konular ele alınmıştır. Hem profesyonel şancılar hem de şan eğitimine yeni başlayan öğrenciler için temel kaynak niteliğindedir ancak başlangıç düzeyindeki şan öğrencisinin kitabı anlamakta zorlanabileceği hususunda vurgulamalar yapılmaktadır. How to Sing, nasıl şarkı söylenmesi gerektiğiyle ilgili vokal biliminin gerektirdiği konuları içeriğinde barındırarak, bilimsel temel dayanaklarla açıklamaktadır. Yazar, basit bir anlatımla, şarkı söylemenin izahlarına değinerek; "açık", "kapalı"," nazal”, "kafanın içinde", "boyunda", "ileride” ve "geride” kavramlarına açıklık getirmiştir. Lehmann’ın savunduğu görüş ses becerisi için sadece teknik bir kılavuzdan öte olup, öğrenmenin genel sanatı üzerine gerçek bir şekilde müzikal ve meditasyonel düşünebilmektir.

Douglas Stanley; Lehmann'ın şarkı söylemeyi bırakıp şan pedagogluğu yapmaya başladıktan sonra sesini kaybettiğini ve bu kitabı yazdığını, hiçbir bilimsel tarafının olmadığını, mantıksız ve dayanaksız kendi teorilerini ürettiğini söyleyerek olumsuz yönde eleştirmiştir. Lehmann, Manuel Garcia’nın öğrencisi olmamasına rağmen, Garcia'nın bilimsel ilkelerinin çoğunu kendi bireysel yaklaşımına dahil etmiştir. Lehmann'ın bu kitabı yazma nedenlerinden biri de; şarkı söylemedeki teknik yeterliliğin, yorumsal güç ve ifadeden daha önemli olduğu düşüncesidir.

Kitabın ilk bölümünde nefes ele alınmıştır. İlk uygulamalara nasıl başlanması gerektiğini fizyolojik olarak açıklamış, artistik şarkı söylemenin nasıl olması gerektiği üzerine tartışmalı bir soru-cevapla izah etmiştir. Şarkı söylemeye başlamadan önce, fiziksel ve zihinsel hazırlık yapmanın önemine dikkat çekmektedir. Yazar, şark1 söylerken; larenks dil, damak ve burun yani sesi üreten bu başlıca mekanizmayı doğru bir şekilde kullanılmasının

\footnotetext{
Kitap İncelemesi: Geliş Tarihi/Received Date: 06.04.2020 Kabul Tarihi/Accepted Date: 10.06.2020

*Sorumlu Yazar/Corresponding Author: Öğr. Gör. Dicle Üniversitesi Devlet Konservatuvarı Diyarbakır, sibelcelik@mail.ru ORCID ID: $\underline{0000-0002-8177-9946}$
}

Atıf/Citation: Çelik, S. (2020) How to Sing. Eurasian Journal of Music and Dance, (16), 375-379. 
önemine vurgu yapmaktadır. Lehmann, doğru bir nefes için en önemli unsurlardan birinin yükseltilmiş bir göğüs olduğuna inanmaktadır. Nefesi düzenleyen karın (abdominal kas) ve diyafram kaslarının işlevlerinin anlaşılması ve gögüs kaslarının gerginleşmesinin gerektiğini anlatır. Sonraki bölümde, "nefes ve dönen hava sesin önde olması” üzerine izahları mevcuttur. Şarkıcının fizyolojik çalışmaları üzerinde durmuş, rezonans boşluklarını (alın, nazal, damak) resimleyerek somutlaştırmaya çalışmıştır.

Postür (duruş) ile ilgili tavsiyesi; şarkıcının egzersiz yaparken, mümkün olabildiğince, kendini yakından izleyebilmesi hatta aynada görebilmesi gerektiğidir. Vücut dik fakat gergin durmamalıdır. Eserin akışına göre vücuduna yön vermeli ve yersiz hareketlerden kaçınmalıdır. Eller, ifadenin yorumlanmasına katılmadan sessizce yana salınmalı veya bir şeye hafifçe dayanmalıdır. Ona göre gereken ilk şey, vücudu kontrol altına almak, sakin ve rahat olabilmektir.

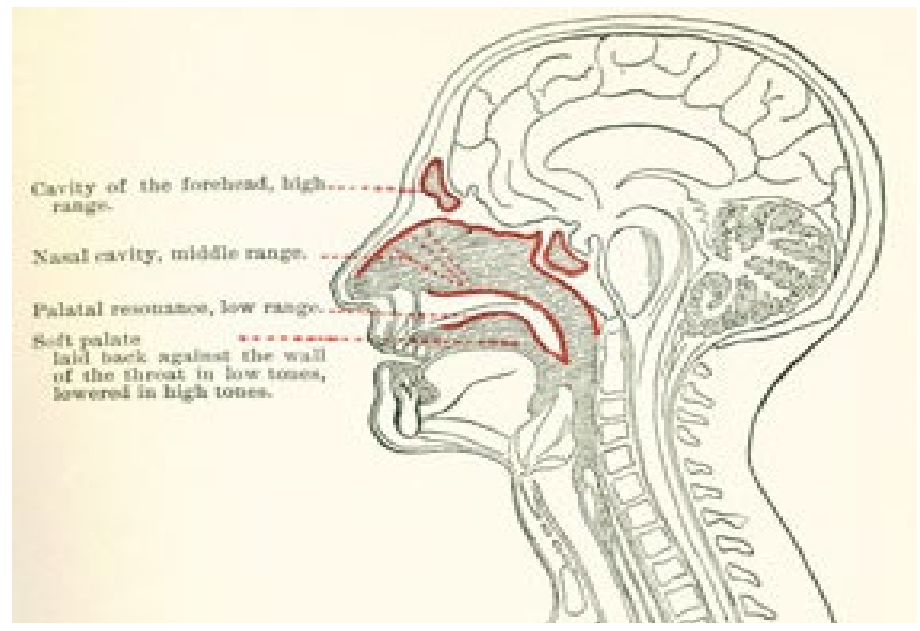

Sekil 1. Rezonans Alanları (Lehmann, 1993, s. 19)

Şekilde yukarıdan aşağıya doğru görüldüğü gibi; alın boşluğu (yüksek tonlar), nazal boşluk (orta tonlar), ve damak rezonansı (düşük tonlar) olarak resmetmiştir. Sonraki bölümde ise sesin dengelenmesi ve biçimi konusunu ele alarak belli yönergelerle belirtmiştir. Larenks çok düşük veya çok yüksek gerilmemeli, serbestçe çalışmalıdır. Şarkı söylemeye ilişkin en iyi ve pratik çalışmanın, "o" ve "oo" ile" ah" sesine benzeyen harflerle başlaması gerektiğini belirtir. Dilin doğru yerde olması ve yerleşmesi için ağız tıpkı esner gibi olmalıdır. Kadın ve erkek seslerinin en pes ses dizilerinde, rezonans baş boşluklarından kesilmekte, ses damakta tınlamaktadır ve bu sayede göğüs rezonansı meydana gelmektedir. Kadife yumuşaklığında "o" hecesi örtülü bir ton hissiyle damağa doğru büyük bir yayın uzaması gibi çıkarılmalıdır. Hemen ardından; vokale başlangıç ve ünlü harfleri izah etmektedir. Ünlü harfleri akustikal olarak nasıl tınladığını tanımlamaya çalışmıştır. "E” ünlü harfi özelliği gereği yüksek ve taşıyıcı bir vokaldir. Böylece tiz tonlarda üst rezonansın kullanılmasında rahatlık sağlar. "A” ünlü harfinde ton, dayanıklı, parlak, kararlı yerleşmiş tınlamaktadır. “O” ünlüsündeyse; ahenkli, esnekliği olan ve göğüs rezonansını andıran derin bir ton hakimdir. O’na göre bu üç ünlü harfin işlevi çok büyüktür, her biri birbiriyle örtüşen bağlantılarla birbirini desteklemektedir. Bu sayede sesin önde olmasını sağladığına değinerek, bunu illüstre ederek somutlaştırmaya çalışmıştır. 
Diğer bölüm, "Nazal söyleme, buruna doğru söyleme” üzerinedir. Nazal ses hakkında açıklamaları mevcuttur. Lehmann, "hanger” kelimesindeki "ng” harflerinin telaffuzundan kaynaklanan nazal sesi örnek göstermiştir. Alman dilindeki "Engel", "lange", "mangel" vb. gibi kelimelerin zenginliğini nazal ses üretimi için bir firsat olarak tanımlamıştır.

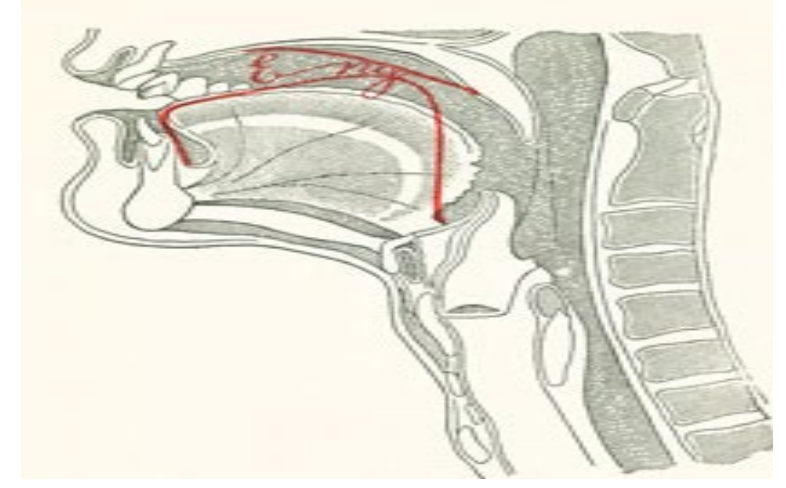

Şekil 2. Nazal Seste Dil ve Damağın Hareketi (Lehmann,1993, s. 40)

Kafa sesini ayrı bir bölümde anlatmıştır. O’na göre kafa sesi kadın ve erkek tüm şarkıcılarda var olan ve anlam kazandıran en değerli materyaldir.

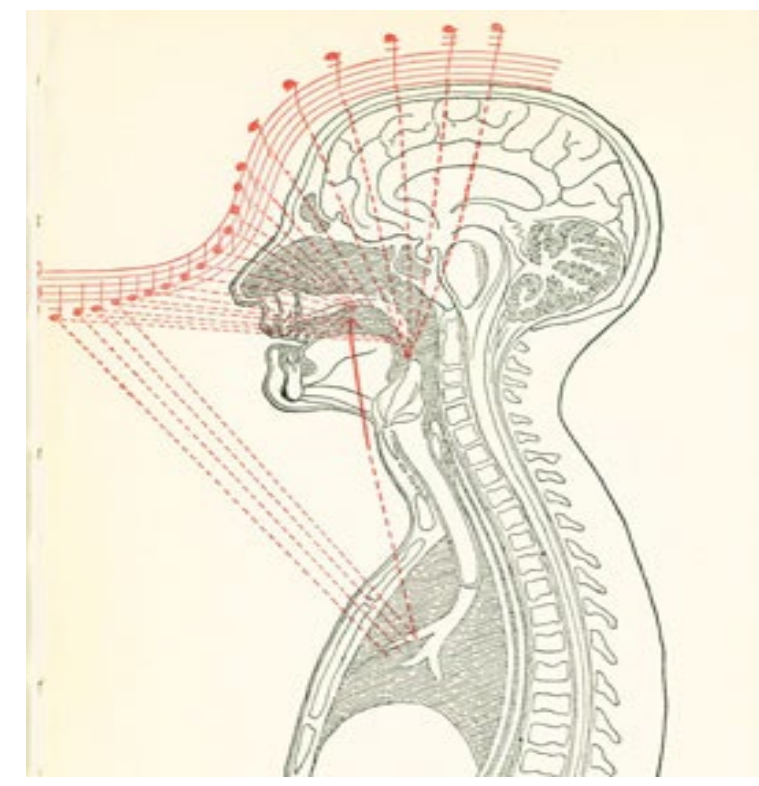

Şekil 2. Soprano ve Tenor Şarkıcıların Vokal Duyuları (Lehmann, 1993, s. 44)

Dil pozisyonunun anlatıldığı bölümde; dilin görevinin larenksin üzerinden gelen nefesi rezonans odalarına iletmek olduğunu belirtir. Dil pozisyonun nasıl olması gerektiğine önem gösterir; tıpkı esner gibi "aho" hecesiyle çalışmaya başlanabileceğini, "aye" ve "o" ile devam ettirilebileceğini söylemektedir. Dil ve dil ucunun asla geriye doğru kıvrılmaması gerektiği hususuna vurgu yapar. Genç seslerin çok fazla yorulmaması için, egzersizlere orta tonlardan başlanması, yarımşar tonlarla önce yukarı doğru ve daha sonra aynı tonla başlayıp, aşağı doğru inmenin 
doğru olduğunu savunur. Diğer tüm egzersizler alt tonlarda başlar ve yukarı çıkar. Egzersizlere, piyano ses yüksekliği ile başlayın, uzun bir crescendo yapın ve yavaş yavaş iyi kontrol edilen bir piyano ses yüksekliğine geri dönün ve bitirin. Lehmann sanat ve disiplinin birbirlerinden ayrılamaz bir bütün olduğunu söylenmektedir.
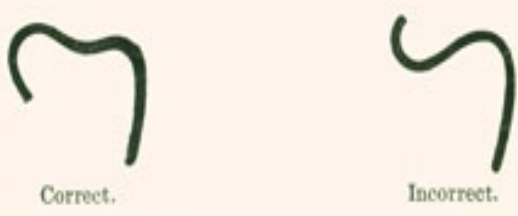

Şekil 3. Şarkı Söylemede Doğru (sol) ve Yanlış (Să̆) Dil Pozisyonu (Lehmann, 1993, s. 47)

Lehmann, aynada çalışmanın yararlı olabileceğini savunarak tüm organların, ağzın, yüzün, sesi üreten çoğu organın fonksiyonunu görebileceğimiz ve kontrol edebileceğimiz kanaatindedir; bu anlamda ayna karşısında çalışmanın yararlı olabileceğini savunmaktadır. Ayrıca kitapta, "burun” ve "burun formunun” anlatıldığı kısa bir bölüm de mevcuttur.

Damakla ilgili anlatılan bölümde; bir şarkıcı için damağın ölçülemeyecek bir öneme sahip olduğuna vurgu yapmaktadır. Daha iyi hissetmemiz için dokunmamızı önerdiği burnun gerisindeki bu yumuşak damak, en iyi şekilde yükseltildiği zaman anlaşılmaktadır. Damağın yükselmesiyle kafa boşluklarındaki rezonans devreye girer ve kafa sesleri oluşur.

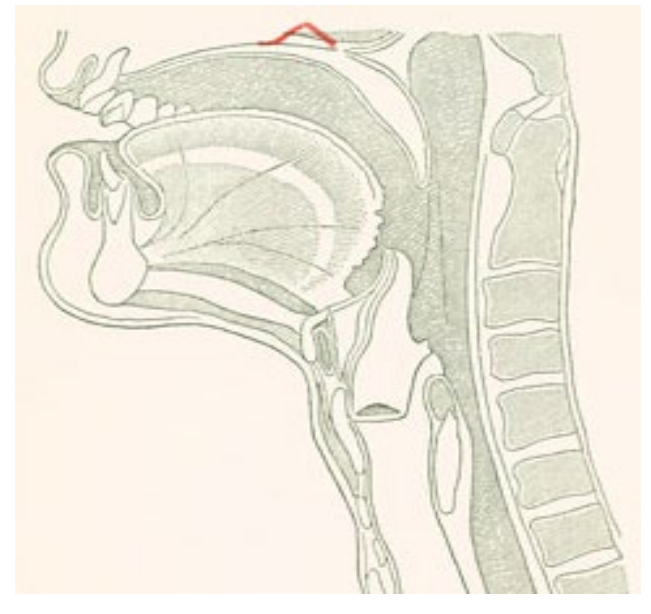

Şekil 4. Yumuşak Damağın Hissedildiği Yer (Lehmann, 1993, s. 60)

Şekilde, damağın hissedildiği en yumuşak nokta (yumuşak damak) gösterilmektedir. Vokal pozisyon ve vokal register üzerinde açıklamalar yapmıştır. Register kavramına ilişkin "ses organlarının (larenks, dil, damak) tek bir pozisyonda ürettiği ses dizileri” tanımını yapmakta ve registerları 3 gruba ayırmaktadır. Bunlar; göğüs, orta ve baş registerlarıdır. Sonraki başlıkta, şarkıcının Berlin konseri deneyiminde hafızasında yer eden şarkıcı Theodor Wachtel'den bahsetmiştir. Onu mükemmel tekniği ve ihtişamı, Wagnerian (Wagnerci) ruhunu taşıması, uzun yıllar sesini çok iyi muhafaza etmesinden dolayı "kusursuz" olarak tabir etmektedir. Diğer bölümde, tiz tonlar, staccato ve tremolodan bahsetmekte, muhtelif tanımları ve buna ilişkin yönergeleri bulunmaktadır. Ağız pozisyonu ve 
konuşma kaslarının birbiriyle olan ilişkisine de değinmektedir. Sonraki bölümde, ünlü harflerin birbirleriyle olan bağlantılarına değinmiştir. "A” ve “e” ünlüsünün parlak olduğuna, ağızda hoş, neredeyse gülümseyen bir pozisyonla söylenmesi gerektiğini belirtmiş, “u” ve “o” ünlülerinin ise, tam tersi olduğunu yani; "karanlık” olduğu tanımını yaparak ifadenin önemli bir etmeni olan dudakları incelemiştir.

İtalyanca ve Almanca başlığında ise; İtalyanların sahip olduğu karakteristik anadilleri gereği, uzun yıllar uygulama yapmayı başarmış olabileceklerini belirtir. "Tuoi”, “miei”, “muoia” örneğiyle tek bir hecenin üç ünlü harfle birleştiğini söylemektedir. Lehmann’a göre; İtalyanlardan ünlü harflerin birbiriyle olan bağlantısını, Fransızlardan ise burun (nazal) tonunun kullanımını öğrenebileceğimizi belirtmektedir. Almanlardan ise, müzikal ifade gücü hepsini geride bırakmıştır. Esasen, burada söz konusu şarkı söyleme ekolleri ve okullarıdır. Sonraki bölüm egzersizlerden oluşmaktadır. Tüm ses türleri için gerekli olan en önemli egzersizlerden bahsetmektedir.

Sonuç olarak; operanın ilk uluslararası divalarından Lilli Lehmann tarafından yazılan bu kitap, çağının teknik ve tıbbi imkânlarını kısıtlı olmasına rağmen şarkı söylemenin rehberi niteliğinde önemli bir kaynaktır. Güçlü ve esnek sesi, mükemmel repertuvarı ile ünlü olmasının yanı sıra şarkı söylemenin her aşamasında; doğru nefes almanın ve vokal artikülenin, dilin, yorumun önemli nüanslarına kadar doğru bir tril yapmanın, kafa seslerinin doğru üretimi, nüansı en doğru teknikleriyle, somutlaştırmaya çalıştırarak kitapta sunmuştur. Kitabın son kısmında dikkat çeken en önemli husus ise, vokal egzersizlerinin yanında, sesin bakımına ilişkin öneri ve yönergelerin mevcut olmasidir. 